\title{
The satiety signaling neuropeptide perisulfakinin inhibits the activity of central neurons promoting general activity
}

\author{
Dieter Wicher $^{1 *}$, Christian Derst ${ }^{2}$, Hélène Gautier ${ }^{3}$, Bruno Lapied $^{3}$, \\ Stefan H. Heinemann ${ }^{4}$ and Hans-Jürgen Agricola ${ }^{5}$ \\ 1. Department of Evolutionary Neuroethology, Max Planck Institute for Chemical Ecology, Germany \\ 2. Center for Anatomy, Charité Berlin, Germany \\ 3. Laboratoire Récepteurs et Canaux loniques Membranaires, RCIM UPRES EA 2647, Université d'Angers, France \\ 4. Department of Biophysics, Center for Molecular Biomedicine, Friedrich Schiller University Jena, Germany \\ 5. Center for Molecular Biomedicine, Friedrich Schiller University Jena, Germany \\ Edited by: Alexander Borst, Max Planck Institute of Neurobiology, Germany \\ Reviewed by: Jane L. Witten, University of Wisconsin-Milwaukee, USA
}

The metabolic state is one of the determinants of the general activity level. Satiety is related to resting or sleep whereas hunger correlates to wakefulness and activity. The counterpart to the mammalian satiety signal cholecystokinin (CCK) in insects are the sulfakinins. The aim of this study was to resolve the mechanism by which the antifeedant activity of perisulfakinin (PSK) in Periplaneta americana is mediated. We identified the sources of PSK which is used both as hormone and as paracrine messenger. PSK is found in the neurohemal organ of the brain and in nerve endings throughout the central nervous system. To correlate the distributions of PSK and its receptor (PSKR), we cloned the gene coding for PSKR and provide evidence for its expression within the nervous system. It occurs only in a few neurons, among them are the dorsal unpaired median (DUM) neurons which release octopamine thereby regulating the general level of activity. Application of PSK to DUM neurons attenuated the spiking frequency $\left(E C_{50}=11 \mathrm{pM}\right)$ due to reduction of a pacemaker Ca ${ }^{2+}$ current through cAMP-inhibited pTRP $\gamma$ channels. PSK increased the intracellular cAMP level while decreasing the intracellular Ca ${ }^{2+}$ concentration in DUM neurons. Thus, the satiety signal conferred by PSK acts antagonistically to the hunger signal, provided by the adipokinetic hormone (AKH): PSK depresses the electrical activity of DUM neurons by inhibiting the pTRP $\gamma$ channel that is activated by $\mathrm{AKH}$ under conditions of food shortage.

Keywords: neuropeptide, Periplaneta, RF-amide, perisulfakinin, DUM neuron, $\mathrm{Ca}^{2+}$ channel, TRP $\gamma$ channel, volume transmission

\section{INTRODUCTION}

The metabolic state is related to general activity. While energy deficiency is related to wakefulness and activity thereby supporting behavioral tasks to overcome this potentially dangerous state, energy excess is related to resting or sleep. People say you cannot study on a full stomach. Although brain areas and messengers involved in this kind of homeostatic regulation have been identified (Castaneda et al., 2005; Vanltallie, 2006), there is less information on underlying mechanisms at the cellular and molecular level. For the study of such mechanisms insects are particularly well-suited models because of the design of their nervous systems. Distinct functions are conferred by identified neurons which is in contrast to the mainly parallel processing within the vertebrate nervous system.

One of the messengers involved in regulating metabolic homeostasis in mammals is cholecystokinin (CCK). This peptide occurs in gut and brain

\footnotetext{
* Correspondence: Dieter Wicher, Department of Evolutionary Neuroethology, Max Planck Institute for Chemical Ecology, Hans-Knöll-Str. 8, D-07745 Jena, Germany. e-mail: dwicher@ice.mpg.de

Received: 05 Sep. 2007; paper pending published: 12 Dec. 2007; accepted: 13 Dec. 2007; Published online: 30 Dec. 2007

Full citation: Frontiers in Cellular Neuroscience (2007) 1:3 doi: 10.3389/neuro.03/ 003.2007

Copyright (C) 2007 Wicher, Derst, Gautier, Lapied, Heinemann and Agricola. This is an open-access article subject to an exclusive license agreement between the authors and the Frontiers Research Foundation, which permits unrestricted use, distribution, and reproduction in any medium, provided the original authors and source are credited.
}

and affects various tasks such as feeding, general activity, memory, and emotional states (Noble and Roques, 2002). When activating the CCK1 receptor, CCK acts as satiety signal and stops food-intake (Strader and Woods, 2005). CCK also reduces general activity thereby promoting sleep (Kapas et al., 1988).

Sulfakinins are insect peptides being structurally and functionally related to the mammalian CCK (Dockray, 2004). They belong to the large family of RF-amides (Nichols, 2003). These peptides bear a common RFamide C-terminus but diverse $\mathrm{N}$-terminal extensions. They are involved in the regulation of various physiological processes in invertebrates and vertebrates. There are two sulfakinins in the cockroach Periplaneta americana, perisulfakinin I (PSK I, EQFDDY-( $\left.\mathrm{SO}_{3}\right)$-GHMRF-amide), which is characterized by a sulfated tyrosine, and the unsulfated PSK II (pQSDDYGHMRF-amide (Veenstra, 1989). PSK I (further referred to as PSK) elicits hindgut contractions while PSK II does not. Also in other insects, such as in Drosophila (Kubiak et al., 2002), unsulfated sulfakinins show no or very weak biological activity. A large variety of physiological responses have been reported for sulfakinins, for example, myotropic effects (Nichols et al., 2002). Antifeedant activity as seen for CCK was also shown for sulfakinins in the locust (Wei et al., 2000) and in the German cockroach (Maestro et al., 2001).

The aim of this study was to unravel the cellular and molecular mechanism of PSK within the nervous system. For this purpose, we have cloned the perisulfakinin receptor (PSKR) and provided evidence that it is expressed within the central nervous system. However, only in a few neurons the receptor is localized in the soma membrane. Among them are 
dorsal unpaired median (DUM) neurons which belong to the octopaminergic system that - as insect counterpart to the mammalian adrenergic system-is involved in the regulation of general activity (Roeder, 2005) as well as in the modulation of peripheral structures such as visceral, heart, and skeletal muscles (Bräunig and Pflüger, 2001). The somata of efferent DUM neurons show, in contrast to most other insect neurons, endogenous electrical activity (Grolleau and Lapied, 2000). Investigations on isolated DUM cell somata indicate that they express various ionotropic and metabotropic receptors (e.g., Grolleau et al., 1996; Washio, 1994; Washio and Tanaka, 1992; Wicher et al., 2006b) despite the fact that there are no synaptic structures. By demonstrating that PSK might be released within a cisterneal system of the extracellular matrix from which it diffuses to the soma membrane we propose a mechanism by which ligands may reach their receptors.

We further show by which mechanism PSK attenuates the excitability of DUM cells. Most intriguingly, PSK down-regulates the same ion current that is up-regulated by adipokinetic hormones (AKHs) which are released under energy deficient conditions (Wicher, 2007; Wicher et al., 2006b).

\section{MATERIALS AND METHODS \\ Cloning of the perisulfakinin receptor (PSKR)}

A combined degenerated PCR/nested RACE strategy was used to clone the PSKR. According to the sulfakinin receptors from Drosophila and Anopheles degenerated primers were constructed amplifying a 1240-bp PSKR. The following primers were used for amplification: forward: $5^{\prime}-$ CTGCTSGGYGTVYTCTGCATGCC-3'; reverse: $\quad 5^{\prime}$-GCAGTASGTGATSGGATTGCAGCA-3'. After direct DNA sequencing, RACE primers were constructed for two rounds of amplification of the cDNA ends. The following RACE primers were used: forward: $5^{\prime}$-GAAAGGACTTCGACGGGAAATCAGACAC-3'; 5'-CATGCCGCAGACAGCTCGAGAG-3'; reverse: $5^{\prime}$ GGGAGTTCCAGATGAGGCTAGCCAG-3'; 5'-CCGAGACTTGAGCGGCCTGCAGA-3'. RACE products were cloned into the pGEM-T vector and sequenced.

\section{Localization of PSK and the PSKR}

A nested PCR approach was used to show PSKR expression in neuronal tissue and in single DUM neurons. The following primers were used for single-cell PCR: forward: 5'-CGTCGTCATTTTTGTGCTGT-3'; 5'-TTCTTAATCTGGCGGTGTCC-3'; reverse: 5'-AACATGGCGTCCAAGAAAAT-3'; 5'TTTGGATGGCCAATCTTCTC- $3^{\prime}$. For single-cell RT-PCR analysis the cytosol of single DUM neurons was harvested with patch pipettes and directly transferred to the RT reaction mixture. RNA from $P$. americana brain and ganglia were isolated using the RNeasy Mini-Kit (Qiagen, Hilden, Germany). RT-reaction was performed with Sensiscript reverse transcriptase (Qiagen). The nested PCR reactions were performed with Advantage Taq 2 polymerase mixture (Clontech, Hamburg, Germany) with initial 60 seconds $94^{\circ} \mathrm{C}$ denaturation followed by 40 cycles 30 seconds $94^{\circ} \mathrm{C}, 30$ seconds $55^{\circ} \mathrm{C}$, and 60 seconds $68^{\circ} \mathrm{C}$. PCR products of the second $\mathrm{PCR}$ reaction were visualized on a $2 \%$ agarose gel. As a positive control we amplified part of a ubiquitously expressed actin gene from $P$. americana in a nested PCR approach using a duplex reaction (PSKR and actin-PCR) as first PCR. To exclude false positive results due to genomic DNA contamination PCR-primers were intron spanning according to the Drosophila and Anopheles genomic sequences. All PCR products were directly sequenced to validate specificity for PSKR.

Two different antibodies to PSK were raised, one in rabbits and one in mice, each to a conjugate of the peptide EQFDDY- $\left(\mathrm{SO}_{3}\right)$-GHMRF-amideglutardialdehyd-thyroglobulin. PSK was synthesized by Bachem Holding AG (Bubendorf, Switzerland). Coupling of peptides to carrier proteins using glutardialdehyde, the immunization protocol for rabbits and mice and the purification of antisera were performed according to (Harlow and Lane, 1988).
The antibody to PSKR used for immunocytochemical demonstration as well as for immunoblots were raised in rabbits against a conjugate of the peptide motif AIKETERHKCR located in the loop between TMS4 and TMS5 coupled to kelim limpet hemocyanin. The peptide was synthesized and coupled to the carrier by Biotrend (Cologne, Germany).

Adult and embryonic $P$. americana were taken from laboratory colonies at the University of Jena (maintained at $27^{\circ} \mathrm{C}$ under $12 / 12$ hours light/dark regime). Animals were anesthetized by cooling under crushed ice and decapitated. Whole ventral nerve cords, midguts, and the sixth abdominal ganglia were dissected from male animals under freshly prepared fixative: $4 \%$ formaldehyde in $0.1 \mathrm{M}$ Millonings buffer ( $\mathrm{pH} 7.35$ ) overnight at room temperature.

Vibratome sections. The preparations were washed in Tris- $\mathrm{HCl}$ buffer (in millimoles: $146 \mathrm{NaCl}, 50 \mathrm{Tris}-\mathrm{OH}$; $\mathrm{pH} 7.4$ ) for 12 hours at $4^{\circ} \mathrm{C}$ on a shaker. Thick sections $(40 \mu \mathrm{m})$ of agar-embedded midguts and sixth abdominal ganglia were cut on a vibratome (Technical Products, St. Louis, USA). The washed free-floating slices were then incubated in rabbit antiPSKR polyclonal antibody diluted 1:500 and in a mouse anti-PSKpolyclonal antibody diluted 1:1000 in a solution of Tris- $\mathrm{HCl}$ buffer containing $2 \%$ normal goat serum, $0.25 \%$ Triton- $X, 3 \%$ skim milk powder, and $0.25 \%$ bovine serum albumin (BSA; MPB). Subsequently, the tissue was washed in MPB overnight and incubated in the Cy3-tagged secondary goat anti-rabbit (GAR) and in the Cy2-tagged secondary goat anti-mouse (GAM) antibody (Jackson, ImmunoResearch Laboratories, Inc., West Grove, USA) for 3 hours at a dilution of 1:800 in MPB.

Whole mounts. The ventral nerve cords of 22-day-old embryos were washed at $10^{\circ} \mathrm{C}$ for 48 hours and incubated for 48 hours in rabbit anti-PSK polyclonal antibody diluted 1:5000 in MPB. The whole nervous systems were then washed in MPB 48 hours and incubated for 48 hours at $10^{\circ} \mathrm{C}$ in a 1:800 GAR-Cy3 dilution.

The vibratome sections and whole mounts were mounted and embedded in Mowiol (Sigma, Deisenhofen, Germany). For the photographic documentation we used the bright-field optics on a Zeiss Axiophot microscope, a Hamamatsu digital camera C4742-95, and OpenLab software (Improvision Limited, Coventry, UK). We performed the following controls: (a) the primary antibody was omitted or replaced with an equivalent concentration of normal serum (negative controls); (b) the secondary antibody was omitted. Under these conditions, cells and fibers remained totally unstained. The cross-reactivity of the PSK antibody with other neuropeptides was tested by ELISA. In a dilution of 1:20000 the antibody recognized the PSK-conjugate with maximal intensity (optical density, $o d=3.0$ ), yet a cross-reactivity to the insect-neuropeptides allatostatin A1, A3, B, proctolin, locustatachykinin, CCAP, AKH I, and corazonin was not detectable. There was, however, a moderate crossreactivity to FMRF-amide conjugate $(\mathrm{od}=1.3)$ and a very weak immunoreactivity to the leucomyosuppressin conjugate ( $\mathrm{od}=0.2)$. Both leucomyosuppressin and FMRF-amide are insect neuropeptides with Cterminal similarity to PSK. As shown in a competitive ELISA, the PSK antibody could solely be inhibited by PSK (total inhibition at $10 \mathrm{pM} /$ well) but hardly by leucomyosuppressin, FMRF-amide, and RF-amide (maximal inhibition by $20 \%$ at $1000 \mathrm{pM} /$ well; Veenstra, unpublished result).

Electron microscopy. After preparation of the abdominal tergites and rapid removal of the gut and fat tissue, the sixth abdominal ganglia were prefixed in situ. After 10 minutes, these ganglia were dissected from ventral nerve cord and continually fixed in vitro. As fixative we used $0.5 \%$ glutardialdehyde, $2 \%$ formaldehyde in $0.1 \mathrm{M}$ HEPES buffer, $\mathrm{pH} 7.35$ for 2 hours at $4^{\circ} \mathrm{C}$, followed by washing overnight in $0.1 \mathrm{M}$ HEPES buffer, and postfixation with $1 \% \mathrm{OsO}_{4}$ in $0.1 \mathrm{M}$ HEPES buffer for 1 hour. After a brief wash, the tissue was dehydrated in a series of alcohol and embedded in Durcupan ACM. Ultrathin sections were cut with Reichert Ultracut E and mounted on Formvar carbon-coated single-slot nickel grids. Sections were first soaked for 10-20 minutes in drops of PBS containing 0.5\% BSA. Incubation with the antibody to PSK (diluted 1:1000) was performed in a 
moist chamber for at least 24 hours at $4^{\circ} \mathrm{C}$. After the grids had been washed 7-8 times by self rotation on a magnetic stirrer, incubation followed with gold ${ }_{12}$-labeled GAR IgG (British Biocell, Cardiff, UK) for 12 hours at $4^{\circ} \mathrm{C}$. After repeated washes with PBS, sections were doublestained with uranyl acetate and lead citrate. Sections were examined with a Zeiss EM 900 electron microscope.

Western blot analysis. Neuronal and intestinal tissue of $P$. americana was ground under liquid nitrogen, the tissue powder was homogenized in $250 \mathrm{mM}$ sucrose, $10 \mathrm{mM}$ triethanolamin hydrochloride $\mathrm{pH} 7.5$ containing Complete Protease Inhibitor (Roche, Mannheim, Germany) and freed from larger particles by centrifugation at $1000 \mathrm{~g}$ for 10 minutes. Finally, the membrane fraction was collected by ultracentrifugation at $200000 \mathrm{~g}$ for 1 hour at $4^{\circ} \mathrm{C}$. For Western blot analysis $200 \mu \mathrm{g}$ protein of both membrane fractions were loaded per lane on a 10\% SDS-PAGE. After transfer to nitrocellulose membranes a standard immunodetection protocol with our PSKR antisera (1:1000 dilution), anti-rabbit IG-alkaline phosphates conjugate (Vector Lab Inc., Burlingame, CA, USA), and BCIP/NBT color reaction was performed.

\section{Electrophysiology}

Isolation of cells was performed as described previously (Wicher et al., 1994). Briefly, the sixth abdominal ganglia of adult cockroaches ( $P$. americana) were excised, desheathed, and incubated for 10 minutes at room temperature in standard bath solution (composition, in millimoles: $190 \mathrm{NaCl}, 5 \mathrm{KCl}, 5 \mathrm{CaCl}_{2}, 2 \mathrm{MgCl}_{2}, 10$ HEPES; pH 7.4) containing $0.5 \mathrm{mg} / \mathrm{ml}$ trypsin (type II, Sigma) and $0.5 \mathrm{mg} / \mathrm{ml}$ collagenase (type I, Sigma). After thoroughly washing off the enzyme the ganglia were stored in saline for at least 1 hour. In the sixth abdominal ganglion, four octopaminergic DUM neurons form a cluster (Eckert et al., 1992). From this DUM cell cluster, which can be easily identified, the neurons were separated using thin metal needles.

Ionic currents of isolated DUM neurons were measured at room temperature using whole-cell patch-clamp. Pipettes having resistances of 0.5-0.8 $\mathrm{M} \Omega$ were pulled from borosilicate capillaries (Hilgenberg, Malsfeld, Germany). Current measurements and data acquisition were performed using an EPC9 patch-clamp amplifier controlled by PULSE software (HEKA Elektronik, Lambrecht, Germany). Data were sampled at $10 \mathrm{kHz}$ and filtered at $2.9 \mathrm{kHz}$. Capacitive and leakage currents were compensated using an on-line $\mathrm{P} / \mathrm{n}$ protocol with a holding potential for leakage measurement of $-110 \mathrm{mV}$. The series resistance remaining after compensation did not exceed $1.3 \mathrm{M} \Omega$. The holding potential $\left(V_{\text {hold }}\right)$ was $-90 \mathrm{mV}$.

Separation of $\mathrm{Ca}^{2+}$ currents in DUM neurons was performed as described elsewhere (Wicher and Penzlin, 1997). The pipette solution used for this separation contained (in millimoles): 100 choline methylsulfate (CMS), $60 \mathrm{CsOH}, 8 \mathrm{CsCl}, 30$ tetraethylammonium (TEA)-Br, $2 \mathrm{Mg}-\mathrm{ATP}, 1 \mathrm{CaCl}_{2}, 3$ EGTA, 10 HEPES. The free $\mathrm{Ca}^{2+}$ concentration was calculated to amount to $63 \mathrm{nM}$ (WEBMAXC v2.20, Patton et al., 2004). The bath solution for $\mathrm{Ca}^{2+}$ current measurements contained (in millimoles): $190 \mathrm{CMS}, 2 \mathrm{CaCl}_{2}$, 10 HEPES, and $0.5 \mu \mathrm{M}$ tetrodotoxin (TTX). When using $\mathrm{Sr}^{2+}$ as charge carrier the $2 \mathrm{mM} \mathrm{Ca}^{2+}$ in the bath solution were substituted by $1 \mathrm{mM}$ $\mathrm{Sr}^{2+}$. For data analysis only such cells were used in which the run-down of currents was less than $10 \%$ within the time required for the investigations ( $\sim 15$ minutes). For separation of $\mathrm{Na}^{+}$currents (Wicher, 2001a) pipette solution contained (in millimoles): $5 \mathrm{NaCl}, 100 \mathrm{CMS}, 30$ TEA-Br, $3 \mathrm{CsCl}, 60 \mathrm{CsOH}, 2 \mathrm{Mg}-\mathrm{ATP}, 1 \mathrm{CaCl}_{2}, 5 \mathrm{EGTA}$, and $10 \mathrm{HEPES}$; the bath solution contained (in millimoles): $60 \mathrm{Na}$ isothionate, $90 \mathrm{CMS}, 40$ TEA-Br, $7 \mathrm{MgCl}_{2}, 1 \mathrm{CdCl}_{2}$, and 10 HEPES. Total $\mathrm{K}^{+}$currents were measured with pipette solution containing (in millimoles): $180 \mathrm{~K}$ gluconate, $10 \mathrm{NaCl}, 2 \mathrm{Mg}$-ATP, $1 \mathrm{CaCl}_{2}$, 5 mannitol, $3 \mathrm{EGTA}$, and 10 HEPES; the bath solution contained (in millimoles): $190 \mathrm{NaCl}, 5 \mathrm{KCl}$, $5 \mathrm{CaCl}_{2}, 2 \mathrm{MgCl}_{2}$, and 10 HEPES. To suppress $\mathrm{Na}^{+}$currents and $\mathrm{Na}^{+}-$ dependent $\mathrm{K}^{+}$currents, $0.5 \mu \mathrm{M}$ TTX was added to the bath. The $\mathrm{pH}$ value was adjusted to 7.4 (bath solutions) and 7.25 (pipette solutions). Liquid junction potentials between pipette and bath solutions were taken into account before establishing the seal.

Spiking of neurons was recorded under current-clamp conditions without current injection. Neurons were bathed in saline (cf. Cells) and patch pipettes (resistance $>1.5 \mathrm{M} \Omega$ ) were filled with a solution composed of (in millimoles) $190 \mathrm{~K}$-gluconate, $5 \mathrm{NaCl}, 1 \mathrm{CaCl}_{2}$, 3 EGTA, $2 \mathrm{Mg}$-ATP, and 10 HEPES ( $\mathrm{pH} 7.25)$. Between recordings (duration 1 second) the cells were held under voltage clamp at a holding potential of $-70 \mathrm{mV}$.

Application or washout of blocking agents was performed by transferring the cells (attached to the pipette tip) within a glass tube into the various solutions. A complete and fast solution exchange within a few milliseconds was achieved by sucking a small amount of solution into the tube.

PSK was obtained from Peninsula (Belmont, CA, USA), LOE908 from Boehringer (Ingelheim, Germany), TTX from Sigma, and $\omega$-agatoxin IVA from Alomone (Jerusalem, Israel).

Data are given as means \pm standard deviation ( $n=$ number of cells) unless otherwise stated. For data analysis including nonlinear fitting procedures Prism 4 software (Graph Pad Software, San Diego, CA, USA) was used. Current-voltage $(I-V)$ relationships for $\mathrm{Ca}^{2+}$ peak currents were fitted taking into account current rectification according to the Goldman-Hodgkin-Katz (GHK) equation

$$
\begin{gathered}
I(V)=G \mathrm{~V}\left\{\left[1-\exp \left(-\left(V-V_{\text {rev }}\right) / 25 \mathrm{mV}\right)\right] /[1-\exp (-\mathrm{V} / 25 \mathrm{mV})]\right\} \\
\left\{1 /\left[1+\exp \left(-\left(V-V_{0.5}\right) / S\right)\right]\right\},
\end{gathered}
$$

where $G$ is the total $\mathrm{Ca}^{2+}$ conductance, $V_{\text {rev }}$ the $\mathrm{Ca}^{2+}$ reversal potential, $V_{0.5}$ the potential for half-maximal activation of total $\mathrm{Ca}^{2+}$ conductance, and $S$ the slope factor of activation (cf. Hille, 1992).

Activation curves were fitted with the Boltzmann equation

$G / G_{\max }=1 /\left\{1+\exp \left[\left(\mathrm{V}-V_{0.5}\right) / S\right]\right\}$,

where $G_{\max }$ is the maximal conductance, $V_{0.5}$ the voltage of half-maximal activation, and $S$ the slope factor.

\section{cAMP assay}

DUM neurons were isolated as described in the previous section; 2 hours after isolation cultures were treated with $10 \mathrm{nM}$ PSK (10-25 minutes) and/ or antisera anti-PSKR 1:100 (1 hour). Subsequently, neurons were fixed for 1 hour with $4 \%$ paraformaldehyde containing $5 \%(\mathrm{w} / \mathrm{v})$ sucrose in phosphate-buffer saline (PBS, pH 7.4). After fixation, cells were washed three times for 5 minutes each in PBS and 5 minutes in PBS containing $0.2 \%$ Triton $\mathrm{X}-100$ (PBS-T). To block non-specific binding of the primary antibody, cell bodies were preincubated with 4\% BSA in PBS-T for 1 hour. Primary antisera (rabbit anti-cyclic-AMP polyclonal antibody, Euromedex, Mundolsheim, France), diluted 1:800 in PBS-T, was applied overnight at $4{ }^{\circ} \mathrm{C}$. After repeated washing in PBS-T, the secondary antibody fluorescein isothiocyanate-labeled GAR IgG (Euromedex) diluted 1:150 in PBS-T containing $1 \% \mathrm{BSA}$ was applied at $20^{\circ} \mathrm{C}$ for 3 hours in the dark. Isolated DUM neuron cell bodies were then rinsed in $4 \%$ BSA in PBS and mounted on glass slides in glycerol/PBS. The fluorescence detection was captured using an Axiocam HRC camera mounted on a Zeiss Axioskop microscope; images were digitized using Axiovision (Carl Zeiss, Jena, Germany). The immunofluorescence quantification used to compare intensity of fluorescence was performed with ImageJ $1.34 \mathrm{~s}$ software (Scion corporation, Frederick, USA).

\section{Measurement of intracellular calcium concentration}

Cells were loaded with Fura-2 (Molecular Probes, Eugene, OR, USA) either by incubation in standard bath solution (cf. above) containing $2 \mu \mathrm{M}$ Fura2/acetomethylester (AM) for 20 minutes or by intracellular perfusion with $10 \mu \mathrm{M} \mathrm{K}_{5}$-Fura-2 added to the pipette solution used for spike recording (for calibration). In order to preserve cellular integrity most experiments were performed with Fura-2/AM loading. 
Free intracellular $\mathrm{Ca}^{2+}$ concentration $\left[\mathrm{Ca}^{2+}\right]_{\mathrm{i}}$ was determined with the fluorescence ratio method. Light exciting Fura-2 at 340 and $380 \mathrm{~nm}$, provided by Polychrome II (T. I. L. L. Photonics, Gräfelfing, Germany), was coupled via an epifluorescence condenser into an Axioskop FS (Carl Zeiss) equipped with a water immersion objective (LUMPFL $40 \times \mathrm{W} / \mathrm{IR} / 0.8$; Olympus, Hamburg, Germany). Emitted light was separated by a $400 \mathrm{~nm}$ dichroic mirror and filtered with a $420 \mathrm{~nm}$ long-pass filter.

$\left[\mathrm{Ca}^{2+}\right]_{i}$ was calculated according to the following equation:

$\left[\mathrm{Ca}^{2+}\right]_{\mathrm{i}}=K_{\mathrm{eff}}\left(R-R_{\min }\right) /\left(R_{\max }-R\right)$.

$K_{\text {eff }}, R_{\min }$, and $R_{\max }$ were determined using DUM neurons permeabilized with $2 \mu \mathrm{M}$ ionomycin and three solutions with different concentrations of free $\mathrm{Ca}^{2+}\left(\mathrm{Ca}^{2+}\right.$ free; $5 \mathrm{mM} \mathrm{Ca}^{2+} ; 500 \mathrm{nM} \mathrm{Ca}^{2+}$; the composition of the $500 \mathrm{nM}$ solution was calculated with WEBMAXC v.2.20, Patton et al., 2004). The values of $K_{\text {eff }}, R_{\min }$, and $R_{\max }$ were $3.72 \mu \mathrm{M}, 0.38$, and 5.9, respectively.

Fluorescence images were acquired using a cooled CCD camera controlled by TILLVision 4.0 software (T. I. L. L. Photonics). The resolution was $640 \times 480$ pixel in a frame of $175 \times 130 \mu \mathrm{m}^{2}(40 \times / \mathrm{R} / 0.8$ objective). Image pairs were obtained by excitation for $100 \mathrm{~ms}$ at 340 and $380 \mathrm{~nm}$, for recording of image series intervening intervals of 10 seconds were chosen. Background fluorescence was subtracted.

\section{RESULTS}

\section{Localization of PSK within the nervous system}

Sulfakinin-immunoreactive (ir) cells have been described in different insect species (e.g., Agricola and Bräunig, 1995; East et al., 1997). In the American cockroach, a specific antibody against PSK recognizes only a few neurons (Agricola and Bräunig, 1995; East et al., 1997). There are 24 PSK-ir cells in the pars intercerebralis that project into the corpora cardiaca (Figure 1A). Using the immunogold technique we stained PSK-ir axon terminals in the storage lobe of the corpus cardiacum indicating that PSK acts as neurohormone (Figures 1B and 1C). Two types of axon profiles differing in the appearance of granula were strongly labeled (Figures 1B and 1C). A third type showed weak PSK-ir which may result from a RF-amide cross-reactivity (not shown).

Furthermore, there is one pair of PSK-ir neurons in the brain, so-called protocerebral descending sulfakinin-ir (PDS) neurons (Agricola and Bräunig, 1995; Figures 1D and 1F). The processes of PDS neurons run contralaterally and unidirectionally through the ventral nerve cord. While they do not form arborizations within all ganglia at early embryonic development (Figures 1D and 1F), three bilateral main branches sprout per ganglion at later stages. Extensive varicosities appear within the branched neurites of PDS neurons during further development as shown for the sixth abdominal ganglion (Figure 1F).

Figure 1. PSK-ir neurons in the central nervous system of Periplaneta. (A) PSK-immunostaining (whole-mount) in adult brain. Bar, $100 \mu \mathrm{m}$. (B,C) Electron micrograms displaying immuno-gold labeling of axon terminals in the storage lobe of the corpus cardiacum. Bar, $100 \mu \mathrm{m}$. (D) PSK-immunostaining (whole-mount) in a 22-day-old embryo. Two cell pairs, the protocerebral descending sulfakinin-ir (PDS1 and PDS2) neurons run contralaterally to the $S E G$. The PDS1 neurons project longitudinally through all ganglia within the ventral nerve cord. By contrast, the PDS2 neurons turn back to the ipsilateral side in the posterior part of the SEG and ascend to the tritocerebrum. (E) Schematic view of $D$. Note the beginning development of arborizations of the PDS1 neurite within the thoracic areas. Other PSK-ir neurons are described in (Agricola and Bräunig, 1995). SEG, subesophageal ganglion; PTG, prothoracic ganglion; MoTG, mesothoracic ganglion; MaTG, metathoracic ganglion; AG, abdominal ganglion; TG, terminal ganglion. Bar, $200 \mu \mathrm{m}$. (F), PSK-immunostaining (whole-mount) in the sixth AG of an adult animal. Note the intense staining of the PDS1 neurite arborizations characterized by varicosities. At each side three bilateral main branches sprout from the primary neurite. Bar, $100 \mu \mathrm{m}$.
Double stainings using a polyclonal rabbit antibody to PSK (Figure 2A) and a monoclonal mouse antibody to octopamine (Figure 2B) visualized the varicosities of PDS neurons as well as the four octopaminergic DUM neurons with their arborizations. Electron microscopical immunocytochemistry revealed two different axon profiles showing PSK-ir. Intense staining was observed in fibers without synaptic contacts (Figure 2E). The other one is equipped with synaptic vesicles and displayed only
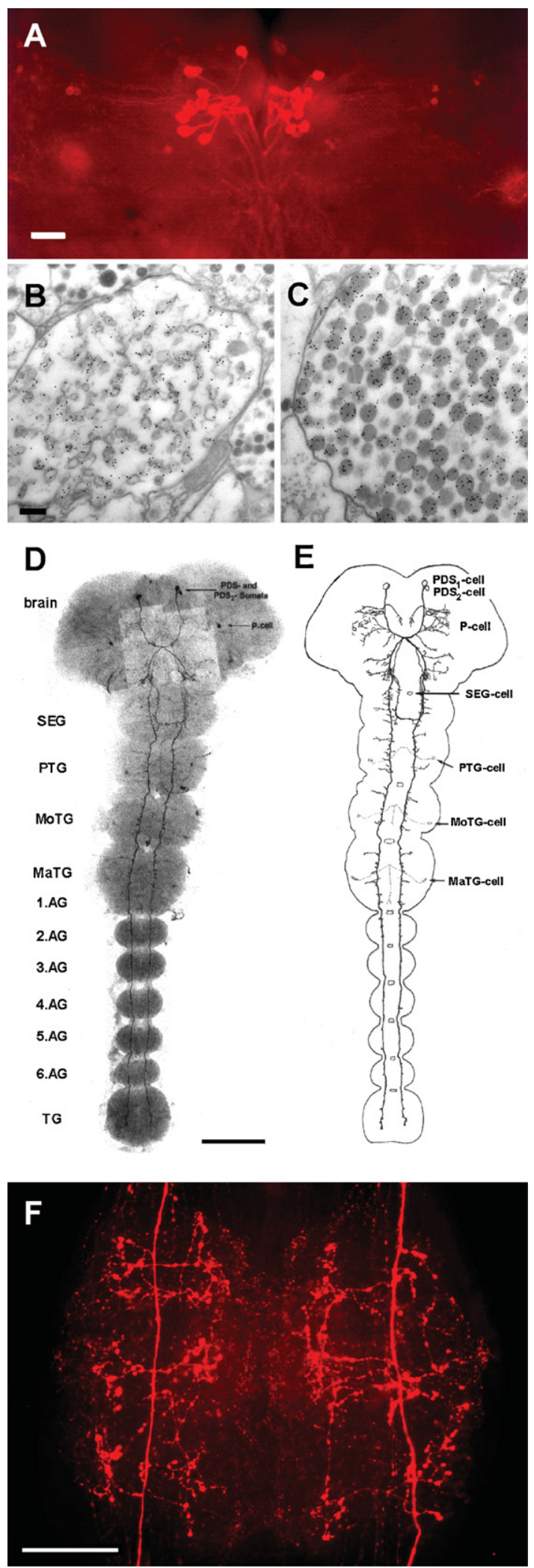

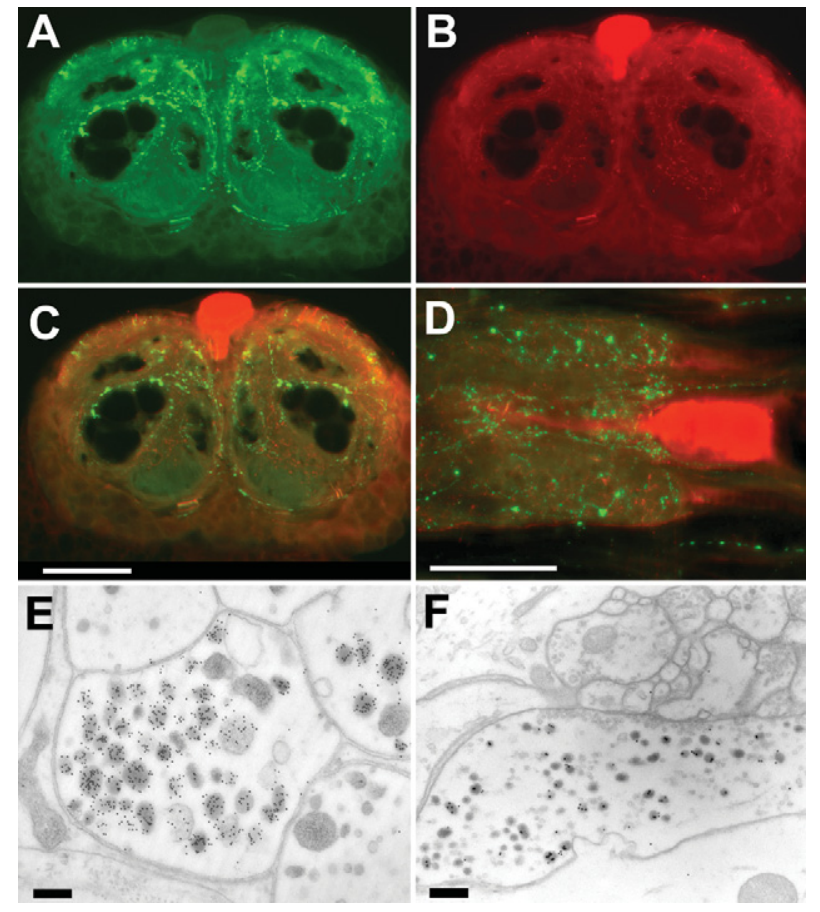

Figure 2. Immunostaining to PSK and octopamine in the sixth AG. (A-C) Frontal slices of the posterior part of the sixth AG, displaying PSK-ir (A), octopamine-ir (B), and merged ir (C). (D) Horizontal slice with double staining to PSK (green) and octopamine (red). Note that PSK-ir fibers occur near the soma of the octopaminergic DUM neuron. Bar, $100 \mu \mathrm{m}$. (E, F) Electron micrograms of two immuno-gold stained axon profiles of the sixth abdominal ganglion. Note the strongly stained granules in $\mathrm{E}$. In these fibers no synaptic contacts were observed. Synaptic contacts are present in fibers showing weak staining (F). Bars, $100 \mu \mathrm{m}$.

moderate staining presumably due to cross-reactivity to RF-amide peptides (Figure 2F). There is no direct innervation of the somata of DUM neurons by the PDS neurons (Figures $2 \mathrm{C}$ and 2D). However, in all preparations $(n=28)$ PSK-immunoreactivity (PSK-ir) appears within the extracellular matrix, the interface between the neuropile and the soma cell layer (Figure 3A). Tiny extensions of this extracellular matrix penetrate the glial layer that surrounds the somata of neurons. This might attribute to the PSK-ir observed near the somata (Figures 2C and 2D).

The presence of PSK within the extracellular matrix indicates that the peptide may be also secreted extrasynaptically as proposed in the concepts of volume transmission (Zoli and Agnati, 1996) or extrasynaptic transmission (Vizi et al., 2004). Using electron microscopy, we detected PSK-ir material within the extracellular matrix channel system (Figures $3 \mathrm{~A}$ and $3 \mathrm{C}$ ). Source of this immunoreactivity is probably peripheral axon terminals containing PSK-ir (Figure 3B). Interestingly, there is also immuno-gold staining within the extracellular space surrounding these axons (Figure $3 \mathrm{C}$ ). These morphological features support the view that PSK may also act via volume transmission.

\section{Molecular cloning and localization of the PSK receptor}

Using a combined degenerated PCR and nested RACE strategy we obtained a 1945 bp cDNA of the PSKR (GenBank acc no. AY865608). This cDNA encodes a 1866-bp open-reading frame for a 622 amino acid protein with significant homology to two Drosophila (23.6\% identity, $32.3 \%$ homology to AAF48875; $29.8 \%$ identity, $41.3 \%$ homology to AAF48879) and one Anopheles (41.9\% identity, $51.4 \%$ homology to AAR28375) sulfakinin receptors. In addition, all typical structural features of a G-protein coupled receptor were identified, including seven transmembrane regions, an extracellular $\mathrm{N}$-terminal region and a cytosolic $\mathrm{C}$-terminus. One noticeable feature of all sulfakinin receptors is the large intracellular linker between TMS5 and TMS6.

A nested PCR approach was used to identify the expression of the PSKR in neuronal tissue. In brain and in thoracic and abdominal ganglia a prominent 362-bp PSKR PCR product was obtained (Figure 4A), verified by sequencing. In addition, in 7 out of 10 isolated actin-positive DUM neurons a PCR signal was obtained (Figure 4B), indicating a significant expression of PSKR in these cells.

A Western blot analysis showed a prominent band at the expected molecular weight of $67.8 \mathrm{kD}$ (arrow in Figure 4C) in the membrane fraction of intestine tissue. In neuronal tissue no specific signal was found indicating that PSKR expression in neuronal tissue is low. This was confirmed by immunocytochemistry (Figure 5). Pronounced PSKRimmunostaining was seen both in midgut and hindgut (not shown). Within the nervous system we found very weak PSKR-ir. Only a few neuronal cell bodies such as those of the DUM neurons (Figure 5B) showed any immunostaining, which was weak compared with that in the gut cells. Within the neuropile, commissural and longitudinal tracts showed PSKRir, presumably associated with axonal membranes (Figure 5C). Interestingly, we also found immunostaining within the extracellular channel system surrounding the somata (cf. Figure 3A).

PSK affects spiking of DUM neurons by modulating ion currents The presence of PSK-like ir nerve endings near the surface of the DUM neuron somata indicates a modulatory control of these octopaminergic cells by PSK-neurons. To test this we investigated the effect of PSK on endogenous spiking of isolated DUM neurons. The experiments revealed that PSK affected spiking at pico- to nanomolar concentrations in a biphasic manner. The highly variable early response observed up to 2 minutes after PSK application was characterized by an acceleration of spiking whereas the uniform late response was always a reduction in spike frequency (Figure 6A). The time courses given in Figure 6B for two cells illustrate the variability of the early response. There was an acceleration of spiking with slow relaxation (upper panel) or oscillations of spike frequencies (lower panel). To estimate the concentration dependence of PSK effects on spike frequency we normalized the maxima of early responses and the means of late responses at 5 minutes presence of PSK (Figure $6 \mathrm{C}$ ). Both the early and the late response were concentration dependent ( $\mathrm{EC}_{50}$ of $21 \mathrm{pM}$ for the early response and $11 \mathrm{pM}$ for the late response).

PSK had little effect on the shape of action potentials. While in some cases the overshoot was enhanced by up to $2 \mathrm{mV}$, the hyperpolarization was never changed. The only significant effect ( $t$-test, $p=0.0093)$ we registered was a shift of action potential threshold from $-28.5 \pm 2.0 \mathrm{mV}$ $(n=5)$ under control to $-24.5 \pm 1.7 \mathrm{mV}$ in the presence of $10 \mathrm{nM}$ PSK for 5 minutes.

The investigation of mechanisms responsible for the different effects of PSK on DUM neuron spiking was initially focused on the late response characterized by reduced pacemaker shift within the interspike interval. We thus tried to identify the pacemaker conductance that was downregulated by PSK.

PSK attenuates the $\mathrm{Ca}^{2+}$ background current. One of the ion currents contributing to pacemaking in DUM neurons is a $\mathrm{Ca}^{2+}$ background current (Heine and Wicher, 1998). This voltage-independent current is constitutively active but negatively regulated by CAMP (Wicher et al., 2004). It is blocked by LOE908, an inhibitor of non-capacitative $\mathrm{Ca}^{2+}$ entry (Wicher et al., 2004), and by the TRP channel blocker 2-APB (Wicher et al., 2006a). The channel conducting the $\mathrm{Ca}^{2+}$ background current is most probably composed of pTRP $\gamma$, an ortholog to the Drosophila TRP $\gamma$ channel subunits which are involved in photoreception (Wicher et al., 2006a). In voltage-clamp experiments with $\mathrm{Ca}^{2+}$ as the only membrane permeating cation, PSK $(1 \mathrm{nM})$ reduced a current that was 


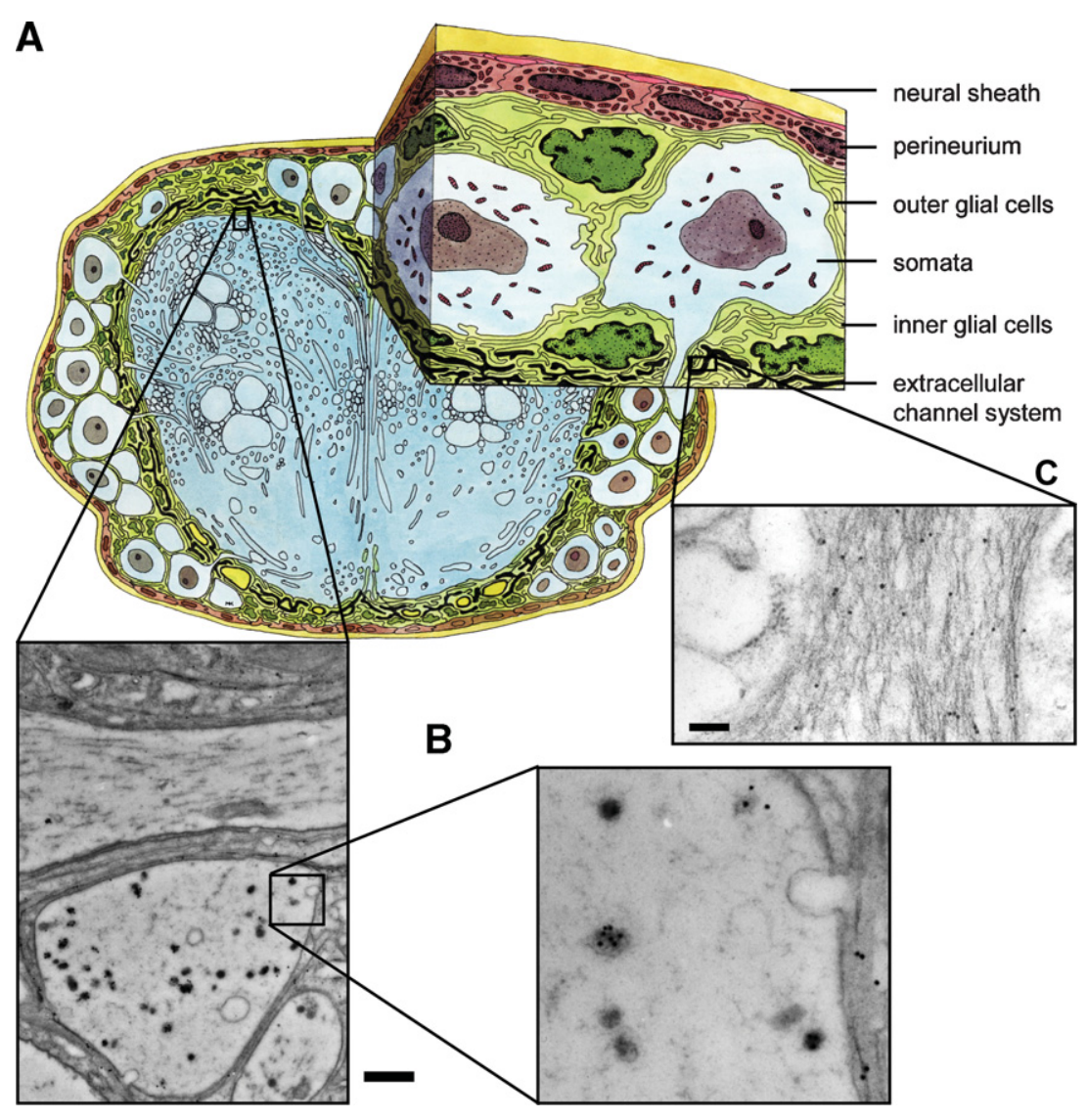

Figure 3. PSK immunostaining in the neuropile and the extracellular matrix. (A) Schematic drawing of a cross-section through the sixth AG. (B,C) PSKir shown by immuno-gold technique occurs in axons of the neuropile (B) and in the channel system of the extracellular matrix (C). Bars, $1 \mu \mathrm{m}(B), 250 \mathrm{~nm}(C)$.

constitutively active in the voltage range between -60 and $-120 \mathrm{mV}$ (Figure 7A). The PSK effect on the membrane current developed quickly after peptide application and saturated after 3 minutes. The recovery after washing off the peptide was $\sim 80 \%$ within 3 minutes (Figure 7B).

A linear extrapolation of the PSK-sensitive current yielded a reversal potential around $0 \mathrm{mV}$ yet the data are compatible with a GoldmanHodgkin-Katz model for a $\mathrm{Ca}^{2+}$ conductance (Figure 7A). When $\mathrm{Ca}^{2+}$ was replaced by $\mathrm{Sr}^{2+}$, PSK still reduced a resting current of comparable size (not shown). After preincubation of neurons with the $\mathrm{Ca}^{2+}$ background current blockers LOE908 or 2-APB, PSK failed to affect the membrane current (Figure $7 \mathrm{C}$ ).

\section{PSK attenuates the $\mathrm{Ca}^{2+}$ background current by increasing the} CAMP concentration. Since cAMP is known to exert an inhibitory control on the $\mathrm{Ca}^{2+}$ background current (Wicher et al., 2004) and on PTRPy channels (Wicher et al., 2006a) we tested whether the reduction of the $\mathrm{Ca}^{2+}$ background current by PSK might be mediated by an increase in the cAMP concentration.

Using an antibody raised against formaldehyde-fixed cAMP, the effect of PSK on the CAMP level was studied. Compared with control experiments (Figures $8 \mathrm{~A}$ and $8 \mathrm{C}$ ), pretreatment with $10 \mathrm{nM}$ PSK increased cAMP-ir in DUM neuron cell bodies (fluorescence intensity: $25.8 \pm 1.1, n=31-$ $35.5 \pm 1.4, n=19$; Figures $8 \mathrm{~A}$ and $8 \mathrm{C}, p<0.001$ ). After relaxation, which is complete after about 3 minutes, the cAMP concentration was stably enhanced within the tested time between 10 and 25 minutes of prolonged PSK incubation. By contrast, in the presence of anti-PSKR (1:100) incubation of DUM neurons with PSK (1 hours) did not result in an increased cAMP level (Figures $8 \mathrm{~B}$ and $8 \mathrm{C}$ ). These results confirm that PSK attenuates the $\mathrm{Ca}^{2+}$ background current via an elevation of the intracellular CAMP concentration.

PSK reduces the intracellular $\mathrm{Ca}^{2+}$ concentration. The $\mathrm{Ca}^{2+}$ background current not only plays a role in pacemaking but also affects the intracellular free $\mathrm{Ca}^{2+}$ concentration $\left[\mathrm{Ca}^{2+}\right]_{\mathrm{i}}$ of DUM neurons (Heine and Wicher, 1998; Messutat et al., 2001; Wicher et al., 2004). The reduction of the $\mathrm{Ca}^{2+}$ background current by PSK is thus expected to attenuate $\left[\mathrm{Ca}^{2+}\right]_{i}$. In order to confirm this we performed $\mathrm{Ca}^{2+}$ imaging experiments in isolated DUM neurons.

The $\left[\mathrm{Ca}^{2+}\right]_{i}$ distribution under control conditions was not always homogeneous. At the basal pole, i.e., near the primary neurite, $\left[\mathrm{Ca}^{2+}\right]_{\mathrm{i}}$ was below $100 \mathrm{nM}$ (Figure 9D). This region is equipped with $\mathrm{Na}^{+}$ channels and responsible for the generation of action potentials in the cell body (Grolleau and Lapied, 2000). $\left[\mathrm{Ca}^{2+}\right]_{\mathrm{i}}$ at the apical pole was frequently somewhat enhanced, also hot spots were observed. Application of PSK $(10 \mathrm{nM})$ caused an overall reduction of $\left[\mathrm{Ca}^{2+}\right]_{\mathrm{i}}$. Within 10 minutes PSK reduced $\left[\mathrm{Ca}^{2+}\right]_{\mathrm{i}}$ from $139 \pm 15$ to $97 \pm 11 \mathrm{nM}$ (Figure 9C).

The results obtained from the investigations of long-lasting PSK effects on the level of ion currents and $\left[\mathrm{Ca}^{2+}\right]_{i}$ support the view that the peptide reduces the $\mathrm{Ca}^{2+}$ background current which was previously shown to be involved in other neuro-modulatory processes (Wicher et al., 2001). The reduction of a current serving as pacemaker seems to be sufficient to explain the reduction of spike frequency by PSK in the late time domain. However, taken into account that the reduction of $\mathrm{Ca}^{2+}$ background current starts shortly after peptide application (Figure 7B), it remains to be shown which mechanism is responsible for the early effect of PSK. The increase in spike frequency obviously requires an over-compensation of 
A

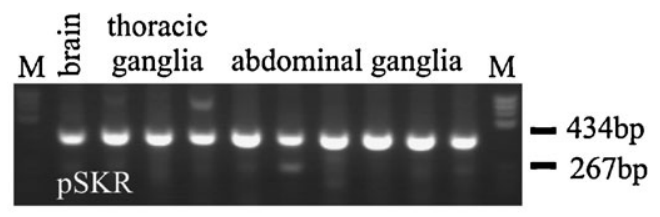

B
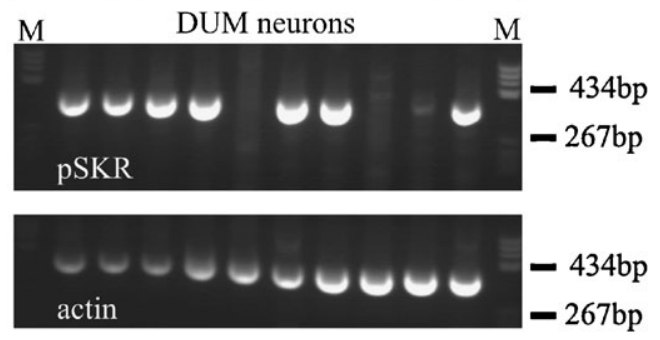

C

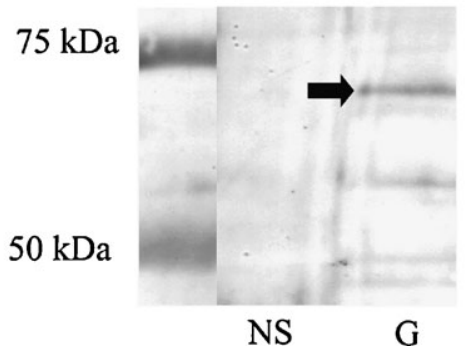

$67.8 \mathrm{kDa}$

Figure 4. RT-PCR and Western blot analysis of PSKR expression. (A) Nested RT-PCR analysis of the PSKR expression in brain and ganglia. A 362 bp PCR product was amplified in all neuronal samples tested. (B) Singlecell RT-PCR analysis of isolated DUM neurons. In 7 out of 10 DUM neurons a PSKR-specific band was found (upper panel). As an endogenous expression control an actin-specific RT-PCR was used (lower panel). M, marker pBR322 DNA BsuRl digested (two marker bands are indicated). (C) Western blot analysis of PSKR expression in nervous system (NS) and gut (G). $A \sim 68-k D a$ band was found in gut only but not in the nervous system. Protein marker bands are indicated in the left lane.

the peptide-induced attenuation of $\mathrm{Ca}^{2+}$ background current by another pacemaker conductance.

PSK neither affects $\mathrm{Na}^{+}$nor $\boldsymbol{K}^{+}$currents. Among the conductances capable of serving as pacemaker in DUM cells there is a sustained component of voltage-gated $\mathrm{Na}^{+}$current (Grolleau and Lapied, 2000). Thus we asked whether PSK might potentiate this current. However, PSK applied at concentrations of 1 and $10 \mathrm{nM}$ revealed that size and kinetics of voltage-gated $\mathrm{Na}^{+}$currents were not affected ( $n=4$ and 6 , respectively; not shown).

In DUM neurons, various types of $\mathrm{K}^{+}$currents occur that not only contribute to action potential shaping but also to the control of pacemaking, as for example, the voltage-gated A-type current (Grolleau and Lapied, 2000). To test whether $\mathrm{K}^{+}$currents might be affected by PSK, we investigated its effect on total outward currents obtained by depolarizations from $-90 \mathrm{mV}$ to potentials ranging from -80 to $+40 \mathrm{mV}$. PSK, at concentrations of 1 and $10 \mathrm{nM}$, did not affect these currents within 2 minutes ( $n=6$, not shown). Similarly, when $\mathrm{Na}^{+}$channels were blocked by TTX thereby inhibiting $\mathrm{Na}^{+}$-activated $\mathrm{K}^{+}$currents, application of $10 \mathrm{nM}$ PSK failed to significantly change size and kinetics of outward currents $(n=6$, not shown).

PSK enhances a voltage-gated $\mathrm{Ca}^{2+}$ current component. The somata of DUM neurons are equipped with voltage-gated $\mathrm{Ca}^{2+}$ channels activating in the low voltage range (Grolleau and Lapied, 1996) and in the high voltage-range (Grolleau and Lapied, 1996; Wicher and Penzlin, 1994; Wicher and Penzlin, 1997). When investigating the effect of PSK on
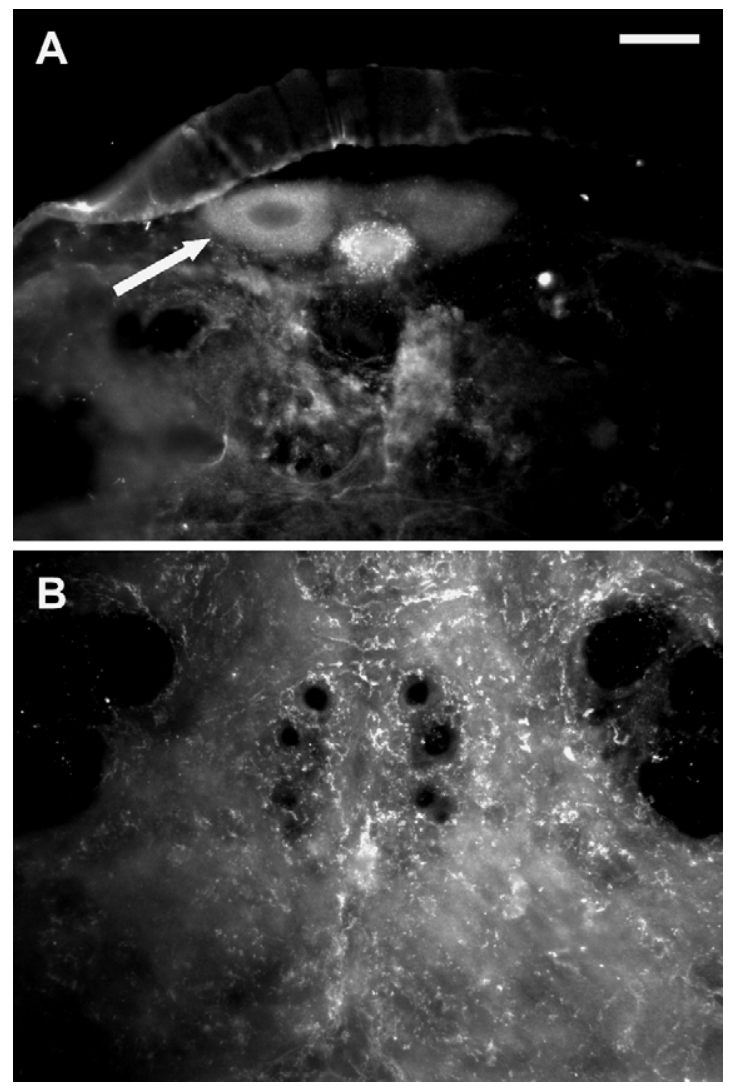

Figure 5. PSKR-like immunostaining in the nervous system. (A) Transversal slice of the posterior part of the sixth abdominal ganglion. The arrow indicates a DUM neuron showing pronounced immunostaining. Bar, $50 \mu \mathrm{m}$. (B) Transversal slice of the sixth abdominal ganglion displaying immunostaining within the neuropile.

voltage-gated $\mathrm{Ca}^{2+}$ currents we recognized that PSK (10 nM) enhanced $\mathrm{Ca}^{2+}$ currents positive to $-60 \mathrm{mV}$ (Figures $10 \mathrm{~A}$ and 10B) but it did not affect current kinetics (Figure 10A). The $I-V$ relationships for peak currents taken before and 2 minutes after PSK application (Figure 10B) showed that the PSK effect is most pronounced in the lower voltage range whereas it is virtually absent positive to $0 \mathrm{mV}$.

PSK shifted the midpoint of the $G-V$ relationship towards more negative potentials and it increased the steepness of its slope (Figure 10C). Fitting data with the Boltzmann equation yielded $V_{0.5}=-22.4 \mathrm{mV}$ and $S=3.9 \mathrm{mV}$ (Control) and $V_{0.5}=-26.8 \mathrm{mV}$ and $S=3.0 \mathrm{mV}$ (PSK). $\mathrm{Ca}^{2+}$ currents show most pronounced $\mathrm{Ca}^{2+}$-dependent inactivation in the voltage range between -30 and $0 \mathrm{mV}$, i.e., where PSK had the strongest effect on the $\mathrm{Ca}^{2+}$ conductance (Figure 10A; cf. Wicher and Penzlin, 1997). Therefore, for a more detailed investigation of the PSK effect $\mathrm{Sr}^{2+}$ was used as charge carrier to avoid this $\mathrm{Ca}^{2+}$-dependent inactivation. However, PSK failed to significantly affect $\mathrm{Sr}^{2+}$ currents (Figure 10D). The PSK effect on $\mathrm{Ca}^{2+}$ channels thus seems to rely on $\mathrm{Ca}^{2+}$ as charge carrier and is possibly related to $\mathrm{Ca}^{2+}$-induced inactivation.

$\mathrm{Sr}^{2+}$ currents activated positive to $-70 \mathrm{mV}$ and reached the maximum at $-20 \mathrm{mV}$. Both potentials were $\sim 10 \mathrm{mV}$ more negative than those for $\mathrm{Ca}^{2+}$ currents which may be accounted for by lower surface charge screening by $\mathrm{Sr}^{2+}$ (Hille, 1992). The $\mathrm{I}-\mathrm{V}$ relationship for $\mathrm{Sr}^{2+}$ peak currents shows a continuous rise from activation threshold to maximum, and it can be well fitted with a GHK equation (Figure 10D, cf. Materials and Methods). By contrast, the $I-V$ relationship for $\mathrm{Ca}^{2+}$ peak currents increases only moderately on jumps ranging from the activation threshold to $-40 \mathrm{mV}$. Positive to $-40 \mathrm{mV}$ there is, however, a steep increase in 
A

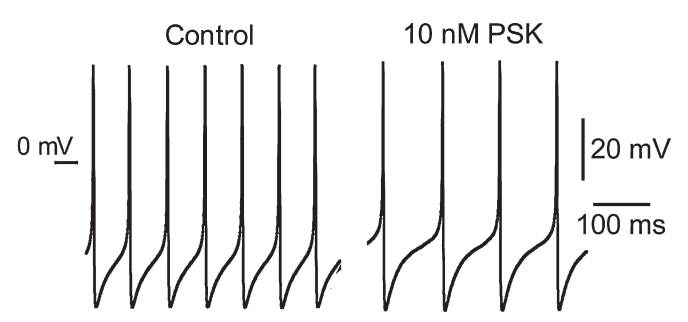

B
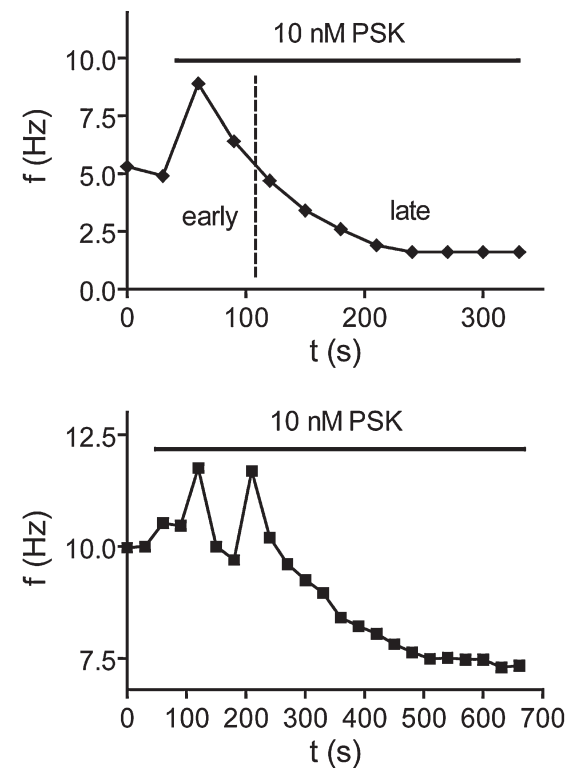

C

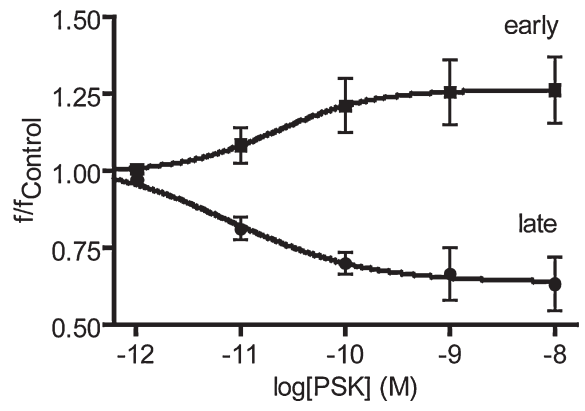

Figure 6. Effect of PSK on spiking of isolated DUM neurons of the sixth abdominal ganglion of Periplaneta. (A) Spike trains recorded under currentclamp conditions (no current injected) before and 4 minutes after application of 10 nM PSK. (B) Time courses of the biphasic PSK effect on spike frequency $f$ for two different neurons. An early response is characterized by an acceleration of spiking (upper panel) which may involve oscillations in frequency (lower panel). In the late response the frequency decreases monotonously until reaching steady state. (C) Concentration dependence of early and late PSK effects on the normalized spike frequency. The early response curve contains frequency maxima recorded up to 3 minutes after PSK application, the late response curve contains frequencies recorded at the end of PSK application where relaxation was complete. Data, means of 6-9 cells; bars, SEM. Doseresponse curves fitted to data are described by $E C_{50}$ of 21 and $11 \mathrm{pM}$ as well as Hill coefficient of 0.94 and 0.72 for the early and the late response, respectively.

current amplitude with increasing depolarization. A simple GHK model fits this $I-V$ relationship less well (Figure 10B).

An explanation for the apparent difference between $\mathrm{Ca}^{2+}$ and $\mathrm{Sr}^{2+}$ currents may be that low voltage-activated (LVA) $\mathrm{Ca}^{2+}$ channels are down-regulated in the presence of extracellular $\mathrm{Ca}^{2+}$. The regulation of a LVA Ca ${ }^{2+}$ current in DUM neurons by the intracellular $\mathrm{Ca}^{2+}$ concentration
A
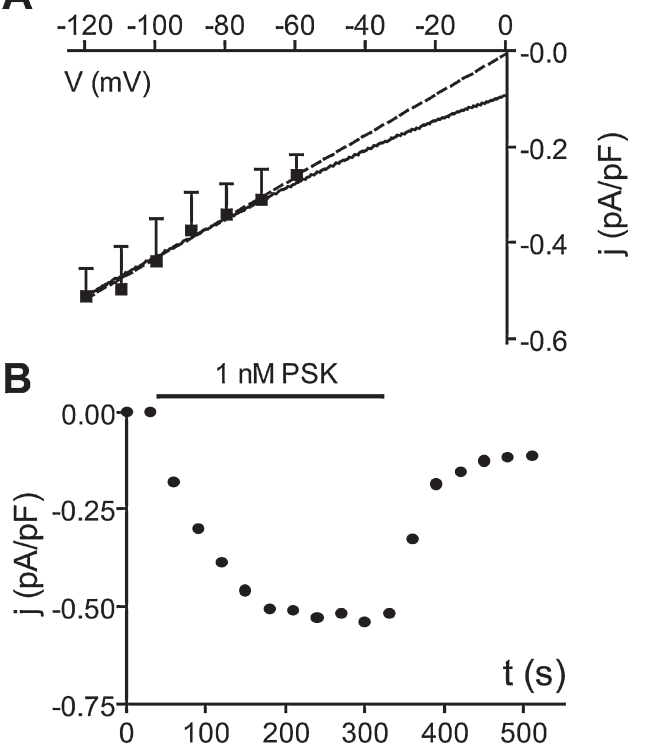

C

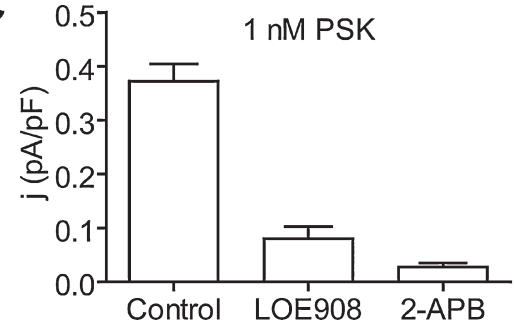

Figure 7. PSK reduces the $\mathrm{Ca}^{2+}$ background current. (A) Current densityVoltage (j-V) relationship of the current reduced by $1 \mathrm{nM}$ PSK (difference current: Control -4 minutes PSK). Currents were measured at the end of $40 \mathrm{~ms}$ lasting voltage jumps from $-120 \mathrm{mV}$ to $-60 \mathrm{mV}$ (holding potential $-50 \mathrm{mV}$ ) and normalized by membrane capacitance of cells. Data, means of six cells. Dashed line, linear approximation; solid curve, fit of GHK model for a $\mathrm{Ca}^{2+}$ conductance. (B) Typical time course of the reduction of membrane current density upon application of $1 \mathrm{nM}$ PSK and recovery upon washing off the peptide. (C) Current density of the current reduced by $1 \mathrm{nM}$ PSK at $-90 \mathrm{mV}$ (obtained as in A) alone (Control) and after preincubation of cells LOE908 $(10 \mu M)$ or 2-APB $(100 \mu M)$. Data, means of six cells; bars, SEM.

has been reported (Grolleau and Lapied, 1996). Furthermore, the $\mathrm{Ca}^{2+}$ background current was shown to be involved in controlling $\left[\mathrm{Ca}^{2+}\right]_{\mathrm{i}}$ (Heine and Wicher, 1998). As described above, PSK attenuates the $\mathrm{Ca}^{2+}$ background current thereby reducing $\left[\mathrm{Ca}^{2+}\right]_{\mathrm{i}}$ (Figure 7 ).

That PSK affected $\mathrm{Ca}^{2+}$ currents preferentially in the lower voltage range might indicate a selectivity to distinct $\mathrm{Ca}^{2+}$ current component(s). PSK has the most pronounced effect on $\mathrm{Ca}^{2+}$ peak currents at $-20 \mathrm{mV}$ (Figure 10E). At this potential the total current mainly results from a current component sensitive to the $\mathrm{P} / \mathrm{Q}$-type $\mathrm{Ca}^{2+}$ channel blockers $\omega$ conotoxin MVIIC and $\omega$-agatoxin IVA (Wicher and Penzlin, 1997). In order to test whether PSK affects this component it was applied in the presence of $\omega$-agatoxin IVA ( $\omega$-AgaTx). $\omega$-AgaTx ( $50 \mathrm{nM}, 2$ minutes) blocked a current activating positive to $-40 \mathrm{mV}$ reaching a maximum at around $-10 \mathrm{mV}$ (Figure 10E). Figure 10F compares the increase in $\mathrm{Ca}^{2+}$ current density elicited by $10 \mathrm{nM}$ PSK under control conditions with that in the presence of $\omega$-AgaTx at $-30 \mathrm{mV}$ where the $\mathrm{P} / \mathrm{Q}$-type current is rather low (cf. Figure $10 \mathrm{E}$ ) and at $-20 \mathrm{mV}$ where this current is predominant. At the latter potential, $\omega$-AgaTx dramatically reduced the PSK effect (by 80\%) whereas it did not significantly change PSK efficacy at $-30 \mathrm{mV}$. The strong reduction of PSK effect by $\omega$-AgaTx at $-20 \mathrm{mV}$ and more positive 


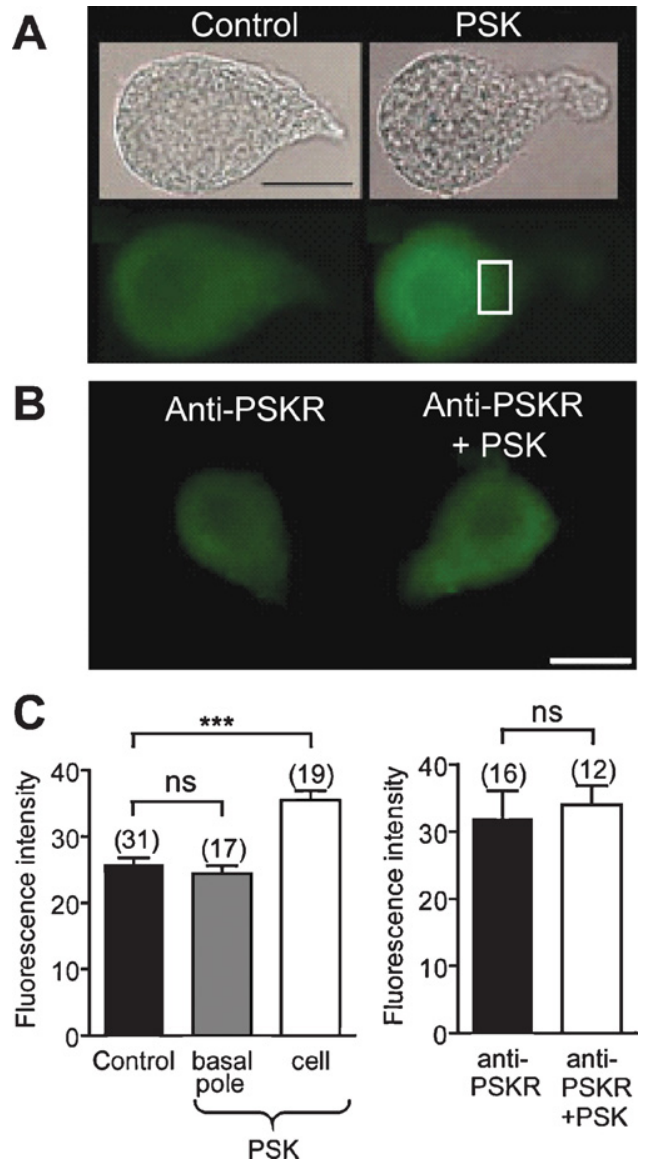

Figure 8. PSK increases the cAMP level in DUM neurons. (A) Bright field images and CAMP immunostainings of isolated DUM neurons in the absence (left) and in the presence of $10 \mathrm{nM}$ PSK (right). (B) CAMP immunostainings in cells incubated with antisera anti-PSKR in the absence (left) and in the presence of $10 \mathrm{nM}$ PSK (right). (C) Histograms showing the intensity of immunofluorescence for the indicated conditions in the basal pole (square, see (A)) and in the cell body. A large increase in cAMP immunostaining intensity was observed in the cell body whereas but not at the basal pole (left). In DUM neurons preincubated with PSKR antisera cAMP immunostaining was not affected by PSK (right). ${ }^{* * *}$ Significantly different, $p<0.001$, Student's $t$ test; ns, not significant. Scale bar, $30 \mu \mathrm{m}$.

potentials (not shown) shows that PSK indeed affects the P/Q-type current. However, the remaining PSK-induced $\mathrm{Ca}^{2+}$ current increase in the presence of $\omega$-AgaTx indicates that PSK also enhances a LVA current. Thus, PSK does not specifically act on a distinct $\mathrm{Ca}^{2+}$ current component.

In the continuous presence of PSK ( $>2$ minutes), we found a reduction of $\mathrm{Ca}^{2+}$ currents activated by voltage commands positive to $-40 \mathrm{mV}$. At the peak of the $I-V$ relationship there was a reduction by $17 \pm 12 \%$ $(n=6)$. To exclude that this effect may result from run-down due to $\mathrm{Ca}^{2+}$ influx during measurements we repeated the experiments using $\mathrm{Sr}^{2+}$ as charge carrier. Under these conditions there was still a reduction by $15 \pm 9 \%(n=5)$. The reduction of voltage-gated $\mathrm{Ca}^{2+}$ current possibly explains the increase in action potential threshold observed in the presence of PSK for $>2$ minutes (cf. above) and it may contribute to the termination of spike frequency oscillations.

\section{DISCUSSION}

Signaling systems involved in general regulation of physiological processes such as the noradrenergic system in vertebrates or the octopaminergic system in insects (Roeder, 2005) supply their messengers

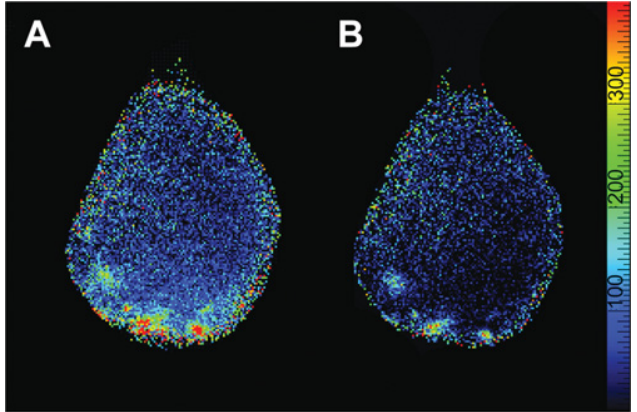

C

D
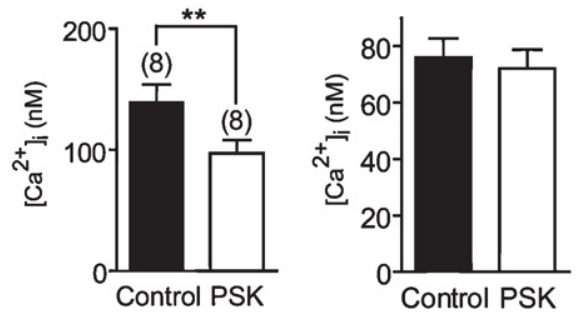

Figure 9. Calcium imaging of the effect of $10 \mathrm{nM}$ PSK on $\left[\mathrm{Ca}^{2+}\right]_{\mathrm{i}}$ in an isolated DUM neuron. (A) Distribution of $\left[\mathrm{Ca}^{2+}\right]_{i}$ under control conditions. The primary neurite of the cell is directed upward, the apical pole is downward. (B) Distribution of $\left[\mathrm{Ca}^{2+}\right]_{i} 8$ minutes after application of PSK. Scale bar, $20 \mu \mathrm{m}$. The color scale gives $\left[\mathrm{Ca}^{2+}\right]$ in $\mathrm{nM}$. (C,D) Mean $\left[\mathrm{Ca}^{2+}\right]_{i}$ in the absence (Control) and in the presence of $10 \mathrm{nM}$ PSK. PSK causes a significant overall reduction of $\left[\mathrm{Ca}^{2+}\right]_{i}$ (paired $t$-test; $p<0.01 ; \mathrm{C}$ ), yet in the basal part $\left[\mathrm{Ca}^{2+}\right]_{i}$ was not significantly changed (D).

throughout the nervous system. The sulfakinin system in Periplaneta is similarly widespread as the projections of the PDS1-neuron run throughout the ventral nerve cord. The arborizations, as demonstrated in the sixth abdominal ganglion, are sufficient to supply the whole ganglion with PSK. Within ganglia, PSK is released both in synaptic as well as in extrasynaptic areas (Figure 3) indicating an important role of volume transmission (e.g., Vizi et al., 2004; Zoli and Agnati, 1996). In addition, since there are 24 PSK-producing neurons in the pars intercerebralis, which project to the corpora cardiaca, a neurohemal organ, a further role of PSK as a hormone is conceivable.

The expression of PSKR in efferent DUM neurons which are involved in the regulation of the animal's activity level (Roeder, 2005) indicates a general activity-regulating role of PSK. Electrophysiological experiments confirmed that PSK indeed modulates the performance of DUM neurons. We have seen that PSK attenuates the spike activity of DUM neurons, which is expected to reduce the octopamine release by these cells. The satiety messenger PSK, which reduces food intake (Maestro et al., 2001), may thus down-regulate the general level of activity. In the opposite physiological context, i.e., under energy-deficient conditions, AKHs are released to mobilize energy reserves. In parallel they up-regulate the activity level that involves stimulation of octopaminergic DUM neurons (Wicher et al., 2006b; Wicher, 2007).

Since there are no synaptic contacts at the somata of insect neurons, the question arises how do chemical messengers approach their receptors localized in the cell body membrane? As the PSK-induced attenuation of the DUM cell spike frequency was observed in isolated somata, PSK receptors are surely present in the cell body membrane as previously reported for other ionotropic and metabotropic receptors such as cholinergic (Grolleau et al., 1996), glutamatergic (Washio, 2002), or peptidergic receptors (Wicher et al., 2006b). Our electron microscopical immunocytochemistry revealed two axon types with differently intense PSK-ir, similar to the situation found in the corpora cardiaca. In both 
A

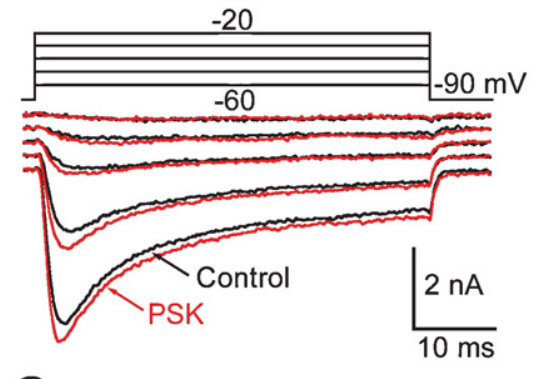

C

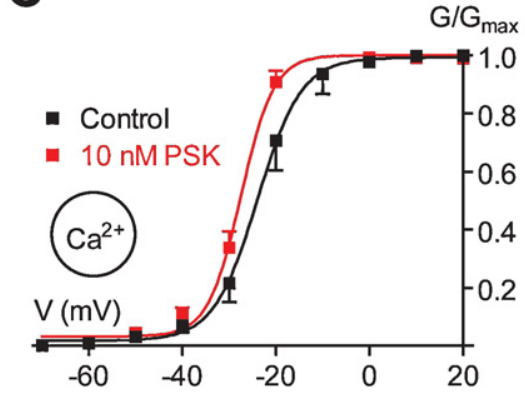

E

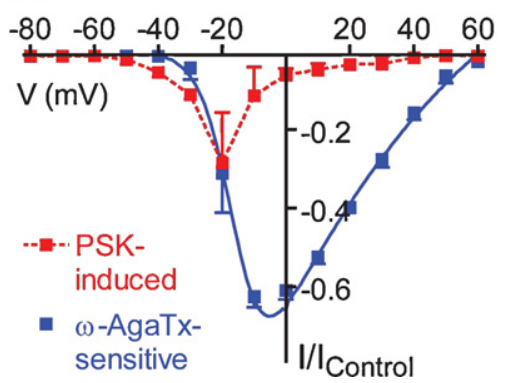

B

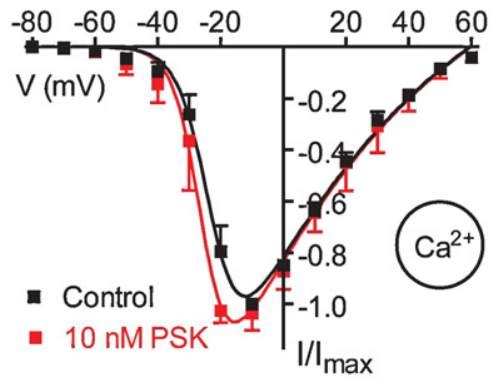

D

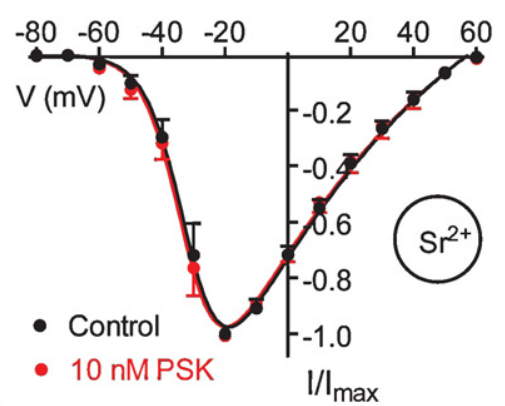

$\mathbf{F}$

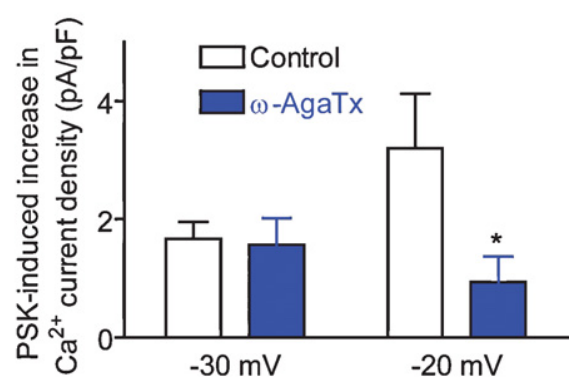

Figure 10. Effect of PSK on voltage-gated $\mathrm{Ca}^{2+}$ currents. (A) Families of $\mathrm{Ca}^{2+}$ currents before and 2 minutes after application of $10 \mathrm{nM}$ PSK. Currents were activated by stepping from a holding potential of $-90 \mathrm{mV}$ to voltages ranging from -60 to $-20 \mathrm{mV}$ in $10 \mathrm{mV}$ increments. (B,C) I-V relationships (B) and G-V relationships (C) for $\mathrm{Ca}^{2+}$ peak currents before (Control) and 1 minute after application of PSK. Data, means of 5-8 cells; bars, SEM. Curves were fitted to the data according to the GHK equation. (D) I-V relationships for $\mathrm{Sr}^{2+}$ peak currents before (Control) and 1 minute after application of PSK. Data, means of five cells; bars, SEM. Curves were fitted to the data according to the GHK equation. (E) I-V relationships for the current produced by $10 \mathrm{nM}$ PSK (1 minute) and the current blocked by $50 \mathrm{nM} \omega$-AgaTx. Currents were normalized to the maximum of the I-V curve under control conditions. (F) Ca ${ }^{2+}$ current density produced by $10 \mathrm{nM}$ PSK (1 minute) under control conditions and in the presence of $50 \mathrm{nM} \omega$-AgaTx.

cases, we assume that the intense staining indicates the presence of PSK while the weak staining may result from RF-amide cross-reactivity which is in accordance with the ELISA results (cf. Materials and Methods). Furthermore, we obtained evidence for the localization of PSK-ir nerve endings near the extracellular matrix, and-most intriguingly-the presence of PSK-ir material within the extracellular matrix indicates that one way for PSK to reach the DUM cell bodies is a paracrine mechanism via volume transmission through this channel system which has extensions to the DUM surface (Figure 3). Alternatively, since PSK is stored in the corpora cardiaca (Figure 1), it is released into the circulation and may penetrate the neural sheath of the CNS to approach the DUM neurons as previously shown for the AKH (Wicher et al., 2006b).

The persisting PSK effect leading to reduced spike activity was accomplished by down-regulation of the $\mathrm{Ca}^{2+}$ background current sensitive to CAMP, LOE908, and 2-APB. We have recently shown that upregulation of this current by an $\mathrm{AKH}$ causes acceleration of spike activity (Wicher et al., 2006a). This was accompanied by an increase in $\left[\mathrm{Ca}^{2+}\right]_{i}$ at the apical pole of the DUM cell indicating that background channels and the signal transduction machinery are localized in this region (Wicher et al., 2004). Interestingly, PSK produced a reduction in $\left[\mathrm{Ca}^{2+}\right]_{\mathrm{i}}$ within the same region (Figure 9).
The early response to PSK involving transient acceleration of spiking was accompanied by an increase in voltage-gated $\mathrm{Ca}^{2+}$ currents. At least two types of currents were found to be affected, the P/Q-type current and an LVA current. Since up-regulation of the $\mathrm{Ca}^{2+}$ background current in DUM neurons was seen to be responsible for a reduction in voltage-gated $\mathrm{Ca}^{2+}$ currents (Wicher, 2001b), the down-regulation of the background current by PSK may simply remove a depressing effect on voltagegated $\mathrm{Ca}^{2+}$ channels. That the amplitude of LVA and P/Q-type currents are under control of $\mathrm{Ca}^{2+}$ has already been demonstrated (Grolleau and Lapied, 1996 and Wicher and Penzlin, 1997, respectively). Since LVA channels also contribute to pacemaking in DUM neurons, their upregulation is expected to increase the firing rate of DUM neurons. The observed transient increase in spike frequency or its oscillation may thus result from the superposition of two contrary effects on pacemaking, namely the up-regulation of voltage-gated $\mathrm{Ca}^{2+}$ currents on the one hand and the down-regulation of the $\mathrm{Ca}^{2+}$ background current on the other.

An experimental analysis of the signal transduction of PSK signaling was beyond the scope of this study. However, two algorithms aimed at predicting the G-protein specificity of receptor coupling were applied to analyze the sequence of PSKR. G protein and receptor interaction feature finding system (GRIFFIN, Yabuki et al., 2005) predicted a coupling to $G_{s}$. 
Since this algorithm stops upon identifying the $\mathrm{G}_{\mathrm{s}}$-binding type it does not provide any information on possible other $G$ protein coupling. The algorithm PRED-COUPLE (Sgourakis et al., 2005) which is also able to model promiscuous coupling predicted a further coupling of PSKR to $G_{q, 11}$ and $\mathrm{G}_{\mathrm{i}, 0}$. The regulation of the $\mathrm{Ca}^{2+}$ background current in DUM neurons by cAMP may be accomplished via different pathways including receptor coupling to $G_{s}, G_{i}$, and $G_{q}$ or even by affecting the NO signaling system (Wicher et al., 2004). Activation of the Drosophila SKR heterologously expressed in mammalian cells most probably leads to $G_{q}$ activation (Kubiak et al., 2002).

\section{CONCLUSION}

We have seen that the gut peptide PSK which also acts within the centra nervous system thereby inhibiting feeding (Maestro et al., 2001; Wei et al., 2000) may be supplied throughout the nervous system and inhibits the activity of octopaminergic DUM neurons. This reduces the octopamine release and thus the general activity of animals (Roeder, 2005). Mammalian peptides mediating satiety signals such as CCK similarly act within the CNS (Nussdorfer et al., 2005). For example, CCK depolarizes rat vagal neurons by acting on background conductances (Peters et al., 2006). Thus the structurally related insect and mammalian neuropeptides PSK and CCK seem to have a similar function in the nervous system in that they down-regulate general activity. The additional involvement of both peptides in the midgut control (not shown) supports the view that various aspects of feeding regulation are evolutionary conserved between insects and mammals.

Under energy deficiency - the opposite physiological condition as PSK is released-insects mobilize energy reserves due to secretion of AKHs. Most intriguingly, AKHs enhance the activity of DUM neurons (Wicher et al., 2006b) that are depressed by PSK. Moreover, not only the $\mathrm{Ca}^{2+}$ background channel is the common target of antagonistic modulation by AKH and PSK, also the CAMP level is regulated by both peptides in antagonistic manner.

Thus the peptidergic control of metabolism involves general regulatory principles conserved in evolution as well as special mechanisms transducing both the message of hunger or satiety.

\section{CONFLICT OF INTEREST STATEMENT}

The authors declare that the research was conducted in the absence of any commercial or financial relationships that could be construed as a potential conflict of interest.

\section{ACKNOWLEDGMENTS}

The authors thank S. Kaltofen, A. Roßner, and A. Schmidt (Jena), and the Center for Electron Microscopy of the Friedrich Schiller University Jena for technical assistance. The Deutsche Forschungsgemeinschaft (Wi 1422/2$4,5)$ supported part of this work.

\section{REFERENCES}

Agricola, H. J., and Bräunig, P. (1995). Comparative aspects of peptidergic signaling pathways in the nervous systems of arthropods. EXS 72, 303-327.

Bräunig, P., and Pflüger, H.-J. (2001). The unpaired median neurons of insects. $A d v$. Insect Physiol. 28, 185-266.

Castaneda, T. R., Jürgens, H., Wiedmer, P., Pflüger, P., Diano, S., Horvath, T. L., TangChristensen, M., and Tschop, M. H. (2005). Obesity and the neuroendocrine control of energy homeostasis: the role of spontaneous locomotor activity. J. Nutr. 135 1314-1319.

Dockray, G. J. (2004). The expanding family of RF-amide peptides and their effects on feeding behaviour. Exp. Physiol. 89, 229-235.

East, P. D., Hales, D. F., and Cooper, P. D. (1997). Distribution of sulfakinin-like peptides in the central and sympathetic nervous system of the American cockroach, Periplaneta americana (L.) and the field cricket, Teleogryllus commodus (Walker). Tissue Cell 29, 347-354.

Eckert, M., Rapus, J., Nürnberger, A., and Penzlin, H. (1992). A new specific antibody reveals octopamine-like immunoreactivity in cockroach ventral nerve cord. J. Comp. Neurol. 322, 1-15.
Grolleau, F., and Lapied, B. (1996). Two distinct low-voltage-activated $\mathrm{Ca}^{2+}$ currents contribute to the pacemaker mechanism in cockroach dorsal unpaired median neurons. J. Neurophysiol. 76, 963-976.

Grolleau, F., and Lapied, B. (2000). Dorsal unpaired median neurones in the insect central nervous system: towards a better understanding of the ionic mechanisms underlying spontaneous electrical activity. J. Exp. Biol. 203, 1633-1648.

Grolleau, F., Lapied, B., Buckingham, S. D., Mason, W. T., and Sattelle, D. B. (1996). icotine increases $\left[\mathrm{Ca}^{2+}\right]_{i}$ and regulates electrical activity in insect neurosecretory cells (DUM neurons) via an acetylcholine receptor with 'mixed' nicotinic-muscarinic pharmacology. Neurosci. Lett. 220, 142-146.

Harlow, E., and Lane, D. (1988). Antibodies. A laboratory manual. (New York, Cold Spring).

Heine, M., and Wicher, D. (1998). $\mathrm{Ca}^{2+}$ resting current and $\mathrm{Ca}^{2+}$-induced $\mathrm{Ca}^{2+}$ release in insect neurosecretory neurons. Neuroreport 9, 3309-3314.

Hille, B. (1992). Ionic channels of excitable membranes, 2 edn. (Sunderland, Sinauer Associates Inc.)

Kapas, L., Obal, F.,Jr., Alfoldi, P., Rubicsek, G., Penke, B., and Obal, F. (1988). Effects of nocturnal intraperitoneal administration of cholecystokinin in rats: simultaneous increase in sleep, increase in EEG slow-wave activity, reduction of motor activity, suppression of eating, and decrease in brain temperature. Brain Res. 438, 155-164.

Kubiak, T. M., Larsen, M. J., Burton, K. J., Bannow, C. A., Martin, R. A., Zantello, M. R., and Lowery, D. E. (2002). Cloning and functional expression of the first Drosophila melanogaster sulfakinin receptor DSK-R1. Biochem. Biophys. Res. Commun. 291, 313-320.

Maestro, J. L., Aguilar, R., Pascual, N., Valero, M. L., Piulachs, M. D., Andreu, D., Navarro I., and Belles, X. (2001). Screening of antifeedant activity in brain extracts led to the identification of sulfakinin as a satiety promoter in the German cockroach. Are arthropod sulfakinins homologous to vertebrate gastrins-cholecystokinins? Eur. J. Biochem. 268, 5824-5830.

Messutat, S., Heine, M., and Wicher, D. (2001). Calcium-induced calcium release in neurosecretory insect neurons: fast and slow responses. Cell Calcium 30, 199-211.

Nichols, R. (2003). Signaling pathways and physiological functions of Drosophila melanogaster FMRFamide-related peptides. Annu. Rev. Entomol. 48, 485-503.

Nichols, R., Bendena, W. G., and Tobe, S. S. (2002). Myotropic peptides in Drosophila melanogaster and the genes that encode them. J. Neurogenet. 16, 1-28.

Noble, F., and Roques, B. P. (2002). Phenotypes of mice with invalidation of cholecystokinin (CCK(1) or CCK(2)) receptors. Neuropeptides 36, 157-170.

Nussdorfer, G. G., Spinazzi, R., and Mazzocchi, G. (2005). Cholecystokinin and adrenalcortex secretion. Vitam. Horm. 71, 433-453.

Patton, C., Thompson, S., and Epel, D. (2004). Some precautions in using chelators to buffer metals in biological solutions. Cell Calcium 35, 427-431.

Peters, J. H., Ritter, R. C., and Simasko, S. M. (2006). Leptin and CCK modulate complementary background conductances to depolarize cultured nodose neurons. Am. J. Physiol. Cell Physiol. 290, C427-C432.

Roeder, T. (2005). Tyramine and octopamine: ruling behavior and metabolism. Annu. Rev. Entomol. 50, 447-477.

Sgourakis, N. G., Bagos, P. G., Papasaikas, P. K., and Hamodrakas, S. J. (2005). A method for the prediction of GPCRs coupling specificity to G-proteins using refined profile Hidden Markov Models. BMC Bioinformatics 6, 104.

Strader, A. D., and Woods, S. C. (2005). Gastrointestinal hormones and food intake. Gastroenterology 128, 175-191.

Vanltallie, T. B. (2006). Sleep and energy balance: interactive homeostatic systems. Metabolism 55, S30-S35.

Veenstra, J. A. (1989). Isolation and structure of two gastrin/CCK-like neuropeptides from the American cockroach homologous to the leucosulfakinins. Neuropeptides 14, 145-149.

Vizi, E. S., Kiss, J. P., and Lendvai, B. (2004). Nonsynaptic communication in the central nervous system. Neurochem. Int. 45, 443-451.

Washio, H. (1994). Effects of putative neurotransmitters on dorsal unpaired median neurons of cockroach (Periplaneta americana) thoracic ganglia. J. Insect Physiol. 40 , 841-847.

Washio, H. (2002). Glutamate receptors on the somata of dorsal unpaired median neurons in cockroach, Periplaneta americana, thoracic ganglia. Zool. Sci. 19, 153162.

Washio, H., and Tanaka, Y. (1992). Some effects of octopamine, proctolin and serotonin on dorsal unpaired median neurones of cockroach (Periplaneta americana) thoracic ganglia. J. Insect Physiol. 38, 511-517.

Wei, Z., Baggerman, G., Nachman, R. J., Goldsworthy, G., Verhaert, P., De Loof, A., and Schoofs, L. (2000). Sulfakinins reduce food intake in the desert locust, Schistocerca gregaria. J. Insect Physiol. 46, 1259-1265.

Wicher, D. (2001a). Peptidergic modulation of an insect $\mathrm{Na}^{+}$current: role of protein kinase A and protein kinase C. J. Neurophysiol. 85, 374-383.

Wicher, D. (2001b). Peptidergic modulation of insect voltage-gated $\mathrm{Ca}^{2+}$ currents: role of resting $\mathrm{Ca}^{2+}$ current and protein kinases A and C. J. Neurophysiol. 86, 2353-2362.

Wicher, D. (2007). Metabolic regulation and behavior: how hunger produces arousal—an insect study. Endocr. Metab. Immune Disord. Drug Targets 7, 1-7.

Wicher, D., Agricola, H. J., Schönherr, R., Heinemann, S. H., and Derst, C. (2006a). TRP $\gamma$ channels are inhibited by CAMP and contribute to pacemaking in neurosecretory insect neurons. J. Biol. Chem. 281, 3227-3236.

Wicher, D., Agricola, H. J., Soehler, S., Gundel, M., Heinemann, S. H., Wollweber L., Stengl, M., and Derst, C. (2006b). Differential receptor activation by cockroach adipokinetic hormones produces differential effects on ion currents, neuronal activity and locomotion. J. Neurophysiol. 95, 2314-2325. 
Wicher, D., Messutat, S., Lavialle, C., and Lapied, B. (2004). A new regulation of noncapacitative calcium entry in insect pacemaker neurosecretory neurons. Involvement of arachidonic acid, no-guanylyl cyclase/cGMP, and cAMP. J. Biol. Chem. 279, 50410-50419.

Wicher, D., and Penzlin, H. (1994). $\mathrm{Ca}^{2+}$ currents in cockroach neurones: properties and modulation by neurohormone D. Neuroreport 5, 1023-1026.

Wicher, D., and Penzlin, H. (1997). $\mathrm{Ca}^{2+}$ currents in central insect neurons: electrophysiological and pharmacological properties. J. Neurophysiol. 77, 186-199.

Wicher, D., Walther, C., and Penzlin, H. (1994). Neurohormone D induces ionic current changes in cockroach central neurones. . Comp. Physiol. [A] 174, 507-515.
Wicher, D., Walther, C., and Wicher, C. (2001). Non-synaptic ion channels in insects basic properties of currents and their modulation in neurons and skeletal muscles. Prog. Neurobiol. 64, 431-525.

Yabuki, Y., Muramatsu, T., Hirokawa, T., Mukai, H., and Suwa, M. (2005). GRIFFIN: a system for predicting GPCR-G-protein coupling selectivity using a support vector machine and a hidden Markov model. Nucleic Acids Res. 33, W148153.

Zoli, M., and Agnati, L. F. (1996). Wiring and volume transmission in the central nervous system: the concept of closed and open synapses. Prog. Neurobiol. 49, 363380. 